\title{
Management of foreign bodies in children's upper digestive tract at Parakou, Benin
}

\author{
Abstract \\ Introduction: Foreign bodies (FB) of the upper digestive tract (UDT) are specific to \\ children. The objective of this study was to report the epidemiological, diagnostic and \\ course of foreign bodies of the digestive tract of children in Parakou.
}

Method: This was a retrospective study conducted from January 2014 to December 2018, in the ENT departments of the regional teaching hospital of Borgou and the Boko Hospital. Included in this study were all children admitted for ingestion of foreign bodies whose age was under 15 years.

Results: Thirty-seven cases of pharyngeal foreign bodies and the child's esophagus were recorded, $46 \%$ of the children's ENT foreign bodies (80cases) during the study period. The sex ratio was 1.64 . The average age of children was $3.61 \pm 2.15$ years with the extremes of 07 months and 08 years. Children under 4 were the most predominant of the series $(70 \%)$. A proportion of $21 / 37$ (56\%) children had consulted in less than 24 hours. Hypersalivation was the main symptom ( $84.85 \%$ of cases). A cervico-thoracic X-ray was performed in all children. The most frequent location of foreign bodies were the hypopharynx and the mouth of the esophagus $(75.68 \%)$. Fibroscopy with a rigid tube under general anesthesia in emergency condition had enabled the extraction of all the foreign bodies. Coin-type non-organic foreign bodies were the most common with 29 cases $(78.4 \%)$. The course was favorable in $95 \%$ of the cases. Complications identified were necrotic lesions in the oesophagus mouth with laryngeal involvement and respiratory distress in a case of flat battery ingestion.

Conclusion: Ingestion of foreign bodies is relatively common within children. The nonorganic foreign bodies recovered were mainly the coins. The natural course was favorable in the majority of the cases. Nevertheless the presence of flat battery in the digestive tract is to be scared.

Volume II Issue 6 - 2019

\author{
Fatiou Alabi Bouraïma,' Spéro HR \\ Hounkpatin,' Marius C Flatin,' Kadidjath \\ Sake,' 'François Avakoudjo, 'Djivédé Akanni,' \\ Hermine Ngamgne Deffo,' Wassi Adjibabi' \\ 'Faculty of Medicine, University of Parakou, Benin \\ ${ }^{2}$ Faculty of Health Sciences, University of Abomey Calavi, Benin
}

Correspondence: Bouraïma Fatiou A. Faculty of Medicine, University of Parakou, Parakou, Benin, BP I23 Parakou, Benin, Email bouraimfa@yahoo.fr

Received: October 31, 2019 | Published: November 29, 2019

Keywords: foreign bodies, hypopharynx, oesophagus, coin

Abbreviations: FB, foreign bodies; UDT, upper digestive tract

\section{Introduction}

Foreign bodies (FB) of oesophagus is a frequent reason for consultation among paediatric ENT emergencies. Infants and young children have a natural tendency to put in their mouths and swallow all the objects close at hand. ${ }^{1,2}$ The diagnosis is usually easy but there is a significant of unknown FB among children especially in asymptomatic cases. That can be a harmless accident or leads to severe complications and becomes life-threatening. ${ }^{3,4} \mathrm{FB}$ removal is carried out under general anaesthesia using a laryngoscope (FB located above cricopharyngeus muscle) or an endoscope with forceps (FB located below cricopharyngeus muscle). The postoperative history is often simple. The goal was to describe epidemiological, diagnostic, therapeutic and evolutionary aspects of upper digestives tract FB in children at Parakou.

\section{Methods}

This was a cross-sectional and descriptive study conducted from 1st January 2014 to 31st December 2018 including all children who: -have been admitted after the ingestion of foreign body and located in upper digestive track (pharynx, cervical and thoracic oesophagus) -performed a radiological assessment (cervico-thoracic x-rays)managed and followed at ENT department of CHUD Borgou and in the operation theatre of Saint Jean de Dieu de Boko Zone hospital (Parakou). Studied parameters were: Age, sex, place of provenance, reason for consultation, circumstance of occurrence, physical examination data, paraclinical investigations data, treatment, and favourable or unfavourable evolution. Data collection, entry and analysis were realized using the software SPSS 17.0 for Windows. Proportions have been compared with chi-square test and the significance threshold was $0.05 \%$.

\section{Results}

\section{Epidemiological aspects}

In total, thirty-seven children who had a foreign body located in their upper digestive tract (UDT) after an ingestion were recruited for a period of 5 years. The mean age was $3.61 \pm 2.15$ years with the extremes 03 months and 08 years. Figure 1 below, shows the distribution of children by age. The sex ratio was 1.64 with a male predominance (23 boys). Most of them were under 4 years of old $70 \%)$ and lived in urban areas $(81.1 \%)$. 


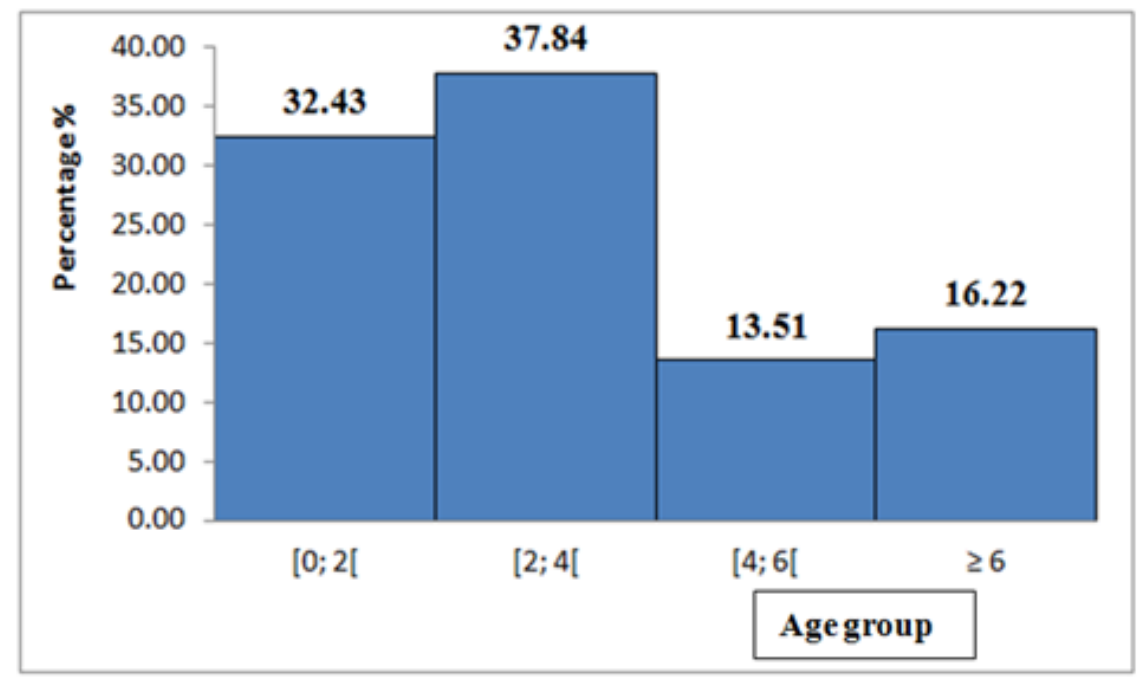

Figure I Distribution of UDT FB in children by age.

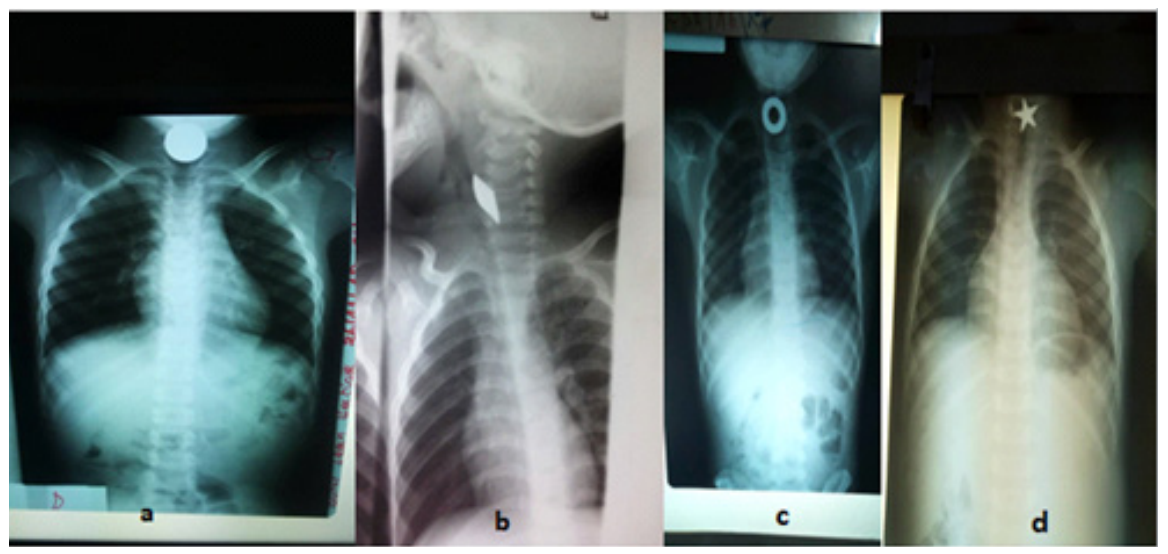

Figure 2 Cervico-thoracic x-rays showing some foreign bodies a: coin, b: metal sheet, c: metal washer, d: metal bead.
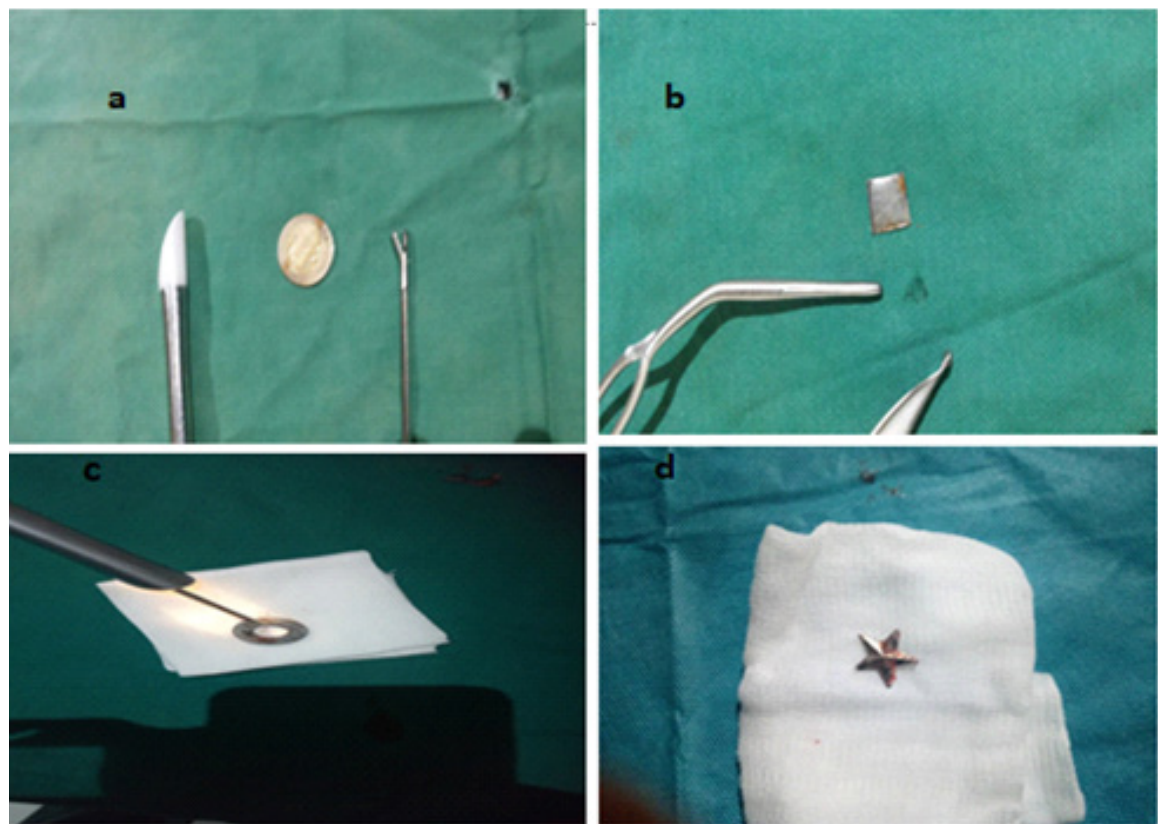

Figure 3 Iconography of the extracted foreign bodies a: coin, b: metal sheet, c: metal washer, d: metal bead.

Citation: Bouraïma FA, Hounkpatin SHR, Flatin MC, et al. Management of foreign bodies in children's upper digestive tract at Parakou, Benin. J Otolaryngol ENT Res. 20I9; I I (6):26I-264. DOI: I0.15406/joentr.2019.1I.00445 


\section{Diagnostic aspects}

In this study, $\mathrm{FB}$ were frequently located in cervical oesophagus $(75.68 \%)$ as shown in Table 1 . The clinical signs observed among children with a FB in their DT were: hypersalivation (84.85\%), dysphagia (42.42\%), and odynophagia $(27.27 \%)$. The foreign body was only inorganic $(100 \%$ of cases). Coin was the main type of FB (74.29\%). Table 2 shows the distribution of FB in UDT among children according to their nature. More than half of children $(60 \%)$ consulted within the first 24 hours, $5.41 \%$ between 24 and $48 \mathrm{~h} .37 \%$ of them were admitted beyond 48 hours (Table 3 ). Frontal and lateral cervico-thoracic $\mathrm{x}$-rays were realized for all the patients and show in $100 \%$ of cases, an opacity corresponding to the foreign body at all levels. Figure 2 below presents some cases of FB images.

Table I Distribution of UDT FB in children according to their sites

\begin{tabular}{lll}
\hline & Size $\mathbf{n = 3 7}$ & $\%$ \\
\hline Hypopharynx-mouth oesophagus (C5_C6) & 8 & 21.62 \\
Cervical oesophagus (C7-T2) & 28 & 75.68 \\
Thoracic oesophagus (T2-T8) & I & 2.70 \\
\hline
\end{tabular}

Table 2 Distribution of FB in UDT among children according to their nature

\begin{tabular}{lll}
\hline & Size $\mathbf{n = 3 7}$ & $\%$ \\
\hline Nature of FB & & \\
\hline Coin & 29 & 78.38 \\
Metal bead & 5 & 13.51 \\
Button cell & 1 & 2.70 \\
Other metallic objects* & 2 & 5.41
\end{tabular}

Other*: washer, metal sheet

Table 3 Distribution of FB in UDT among children by consultation period

\begin{tabular}{lll}
\hline & Size $\mathbf{n = 3 7}$ & $\%$ \\
\hline$[0-12 \mathrm{~h}[$ & $\mathrm{II}$ & 29.73 \\
{$[12-24 \mathrm{~h}[$} & 10 & 27.03 \\
{$[24-48 \mathrm{~h}[$} & 2 & 5.41 \\
$\geq 48 \mathrm{~h}$ & 14 & 37.84 \\
\hline
\end{tabular}

\section{Therapeutic aspects}

For all the patients, the extraction was performed using an endoscopy. Hypopharyngoscopy with a rigid laryngoscope was the surgical procedure mostly used in practice $(59.46 \%)$ and following by rigid esophagoscopy $(40.5 \%)$. Hospitalisation was the predominant follow-up method (94.59\%). Two cases $(5.41 \%)$ followed an ambulatory treatment. The mean duration of hospitalisation was $2.11 \pm 2.56$ days and varies from 1 to 14 days. Most of the children $(63 \%)$ were put on painkillers when the FB is extracted within 48 hours after ingestion. Whereas some children (37\%) with a long stay of FB, were put under antibiotics and corticosteroids after endoscopy. The evolution was in majority of cases favourable (94.60\%); only two cases lead to complications. The first one was an ingestion of button cell by an 8 month old child; the second one had an oesophageal oedema.

\section{Discussion}

\section{Epidemiological aspects}

It is common to underline that only children suffer from FB in UDT. But these frequent ingestions are not well known. The real incidence cannot be determined. Many children swallow objects and that remains unknown. It is estimated that approximately $40 \%$ of FB ingestions are not diagnosed. ${ }^{2,5}$ It is most often domestic accident. In this study, $70 \%$ of children who swallowed FB were under 5 years old. Figueiredo et al., ${ }^{6}$ reported in 2008 (Brazil) that children were the most exposed to FB in digestive tract and 1 to 4 years old children were the most affected. ${ }^{6}$ The same observation has been made by other authors. ${ }^{7,8}$ That accident could be explained by the prehension age around the second year of life and the turbulent character of young children during oral stage.

Male predominance is noted in the majority of studies including the one conducted by Mahafza, who reported a high male predominance at $53 \%$ ( 280 cases) against $47 \%$ of girls ( 247 cases $){ }^{4}$ Lakhdar- Idrissi and Delport also found the same predominance respectively at $59 \%$ and $55 \%{ }^{2,9}$ That was the case in our study with $57.50 \%$ of boys. Boys are the most exposed because of their higher turbulence, daring and the nature of their games.

\section{Diagnostic aspects}

Sharp objects ingestion was an emergency if the oesophagus is affected due to the risk of perforation and haemorrhage. Long objects (superior to $6 \mathrm{~cm}$ ) and large objects «foam» which, lead to an occlusive syndrome require an urgent extraction. So Lakhdar-Idriss in Morocco in 2011, found $66.6 \%$ of consultation during the first 24 hours. $^{2}$ The mean consultation period was 12 hours and the FB removal period was 7.5 hours according to Togo in Mali. ${ }^{10}$ In this study, $60 \%$ of children were admitted during the first 24 hours. That can be explained by the following factors: self-medication, recourse to traditional healers, and the lack of financial means. ${ }^{1}$

A detailed medical history remains a crucial step for the detection of the FB nature, the time of ingestion, the circumstances and the clinical signs observed by the family. A FB can generate especially when it is located in upper digestive tracks, retrocervical pain, acute dysphagia, hypersialorrhea, cough, respiratory distress odynophagia, and vomiting sometimes. But the child can remain asymptomatic even for oesophageal FB. ${ }^{2,4}$ The same observation is made in this study at Parakou. Hypersialorrhea and dysphagia were the main symptoms. FB were inorganic $(100 \%)$ with a coin predominance $(74.3 \%)$. According to Mahfaza in Jordania, coin was the main oesophageal FB $(68 \%) .{ }^{4}$ With modern technology, we discover new FB such as "button cell" of calculators, electronic games and acoustic device. The caustic damages and burns caused by button cell make its ingestion potentially dangerous. ${ }^{3,5}$ FB in UDT (pharynx/oesophagus) are often located on cricopharyngeus muscle, aortic impression and before the oesogastric junction. According to Togo et al ${ }^{10}$ cricopharyngeus muscle has been reported as the site of FB in respectively $69.45 \%$ and $89 \%$ of cases. The main site in our study was the upper third of cervical oesophagus. ${ }^{4,10}$

A radiological assessment is important for any suspicious case of FB ingestion and shows an opacity projected on the oesophageal area. Standard x-rays are classic standard investigations. Metal 
detectors have been proposed as alternative for FB which, contain metals. ${ }^{11,12}$ Most of FB ingested and located in UDT are radioopaque, visible on frontal and lateral cervico-thoracic x-rays. It's the first-line investigation recommended by authors. ${ }^{2-4}$ This allows the physician to confirm most of radio-opaque FB diagnosis, to define its site, configuration, number and size. It also helps in identifying the signs of complications (perforation): gas images in favour of: pneumothorax, pneumoperitoneum, pneumomediastinum or subcutaneous emphysema. ${ }^{2,10}$ Frontal cervico-thoracic $\mathrm{x}$-rays have been performed in all the patients with an opacity reflecting a FB. Oesophagogastroduodenoscopy (OGD) and an upper gastrointestinal series (UGI) have not been performed due to the ease of standard $\mathrm{x}$-rays to establish the diagnosis and remove radio-translucent $\mathrm{FB} .^{2}$

\section{Therapeutic aspects}

FB extraction is performed with a laryngoscopy when it is above cricopharyngeus muscle and through an endoscopy when located under that limit, using a sedation or general anaesthesia with an intubation at best. That's possible in $99 \%$ of cases. It's imperative to have the following types of forceps: " rat-tooth » or " crocodiles ». ${ }^{2}$ Kacouchia et al, Sink et al reported respectively $81.1 \%$ and $99.1 \%$ of patients who underwent a FB extraction with an endoscopy. ${ }^{13,14} \mathrm{Few}$ studies report the failure of that extraction method. The site and FB nature seem to be the factors leading to failure according to some authors. In some regions facing a lack of technical capacity means, the method used was Foley catheter with a balloon for $43.2 \%$ of patients. That management of FB in oesophagus upper third is performed by anaesthetist from Tchad medico-surgical centre in Africa. It is less risky and significantly less expensive but the rate of failure is $12.5 \% .^{15}$ FB in oesophagus can lead to severe complications like perforations and severe infections (mediastinitis, pneumonia). The mortality is low in our study but reached $20 \%$ in other ones. ${ }^{6,15}$ Complication occurrence depends on the physician's experience, the FB nature, site, period of management and technical capacity means. ${ }^{5,10}$ A case of button cell ingestion in an 8 months old child leads to necrotic damage of UDT with a respiratory distress. Those lesions already described are related to the electrochemical nature of button cells. Prolonged mucosa contact cell and especially its content extravasation (made of lithium and hydroxide) are responsible of necrosis due to the caustic lesions. ${ }^{2,3,5}$ An oesogastric endoscopy is necessary after a button cell extraction to detect eventual secondary ulceration lesions.

\section{Conclusion}

FB of UDT is a frequent accident in ENT department. Children are the most affected especially boys. Cervical oesophagus is the predominant site. FB are inorganic and coins in the majority of cases. Radiological assessment helps to establish the diagnosis by showing radio-opaque FB. Endoscopy has a crucial role for the diagnosis and treatment. Parents information and education programs on the dangers and risks related to FB ingestion in children, especially on button cells should be developed.

\section{Acknowledgements}

\section{Conflicts of interest}

The authors declare that they have no conflict of interest.

\section{Funding}

None.

\section{References}

1. Hounkpatin SHR, Avakoudjo F, Agossou J, et al. Les urgences ORL pédiatriques au Centre Hospitalier Départemental du Borgou de Parakou. Rev. Afr. Anesth. Méd. Urg.2012; 17(3) :25-30.

2. Lakdhar-Idrissi M, Hida M. Foreign body ingestion in children: 105 case reports. Arch Pediatr. 2011;18(8):856-862.

3. Kaboré A, Sanou M, Nagalo K, et al. Complications of foreign bodies of button batteries in children: About two cases. $J$ Pediatr Pueric. 2019;32(1):35-38.

4. Mahafza T, Batieha A, Suboh M, et al. Esophageal foreign bodies: A Jordanian experience. Int J Pediatr Otorhinolaryngol. 2002;64(3):225227.

5. Hesham A, Kader H. Foreign body ingestion: children like to put objects in their mouth. World J Pediatr. 2010;6(4):301-310.

6. Figueiredo RR, Azevedo AA, Kos AOF. Complications of ENT foreign bodies: a retrospective study. Braz J otorrhinolaryngol. 2008;74(1):715.

7. Mishra A, Shukla GKBN. Oral foreign bodies. Indian J pediatr. 2000;67:267-269.

8. Deguenonvo REA, Ndlaye M, Loum B, et al. Foreign bodies of the esophagus about 212 cases. Méd d'Afr Noire. 2009;56(7):410-416.

9. Delport CD, Hodkinson PW, Cheema B. Investigation and management of foreign body ingestion in children at a major paediatric trauma unit in South Africa. African J Emerg Med. 2015;5(4):176-80.

10. Togo S, Ouattara MA, Li X, et al. Management for esophageal foreign bodies: about 36 cases. Pan Afr Med J. 2017; 27:207.

11. Olivier J, Joppich M JI. Identification and topographic localization of metallic foreign bodies by metal detector. J Pediatr Surg. 2004;39(8):1245-1248.

12. Lee JB, Ahmad S GC. Detection of coins ingested by children using a handheld metal detector: a systematic review. Emerg Med J. 2005;22(12):839-844.

13. Kacouchia N, N' Gattia KV, Kouassi M, et al. Les corps étrangers des voies aéro-digestives chez l'enfant. Rev Col Odonto-stomato Afr. Chir. Maxi-fac. 2006;13(3):35-39.

14. Sink JR, Kitsko DJ, Mehta DK. Diagnosis of Pediatric Foreign Body Ingestion: Clinical presentation, PhysicalExamination, and Radiologic Findings. Ann OtolRhinol- Laryngol. 2016;125(4):342-350.

15. Lamblin A, Derkenne C, Schwartz A, et al. Treatment of foreign bodies in the upper third of the esophagus without endoscopy: is it a challenge for practitioners working in isolation? Pan African Medical Journal. 2018;30:42.

None. 